\title{
Global Leadership Development: A Phenomenological Study
}

\author{
Satya Subrahmanyam ${ }^{1}$ \\ ${ }^{1}$ Department of Business \& Leadership, Tishk International University, Erbil, Iraq \\ Correspondence: Satya Subrahmanyam, Tishk International University, Erbil, Iraq. \\ Email: satya.sub@ishik.edu.iq
}

Received: April 10, 2019

Accepted: May 27, 2019

Online Published: June 1, 2019

doi: 10.23918/ijsses.v5i4p101

\begin{abstract}
Globalisation has actually quickly developed throughout the preceding 30 years to the aspect in which it is far a reality nowadays. Corporates on this brand-new global structure ought to deal with multinational, multi-lingual and multi-cultural scenarios with global thinking and global abilities. Global corporates are faced with the complexity of vibrant forces of variety, instability, haziness and interdependence. These forces are driving a prolonged requirement for global leaders who have the unique gain that allows them to address and lead properly. With the application of Moustaka's phenomenological research study technique, an effort was made to observe the practices of business leaders who have actually acknowledged them as crucial for their improvement into global leaders. The practices observed such as a) Raise through the direct, global and multicultural governance; b) Require a totally merged set of global leadership details, how to correctly satisfy its functions; c) Boost and take a look at naturally, energetically utilizing advertisement hoc finding out methods, some of the discoveries revealed by the global leaders which assisted them in their change.
\end{abstract}

Keywords: Globalisation, Corporate Leadership, Global Leadership, Leadership Development, Phenomenological

\section{Introduction}

The nature of performing business has actually been undergoing through a lively stage due to the extreme modifications taking place in society due to technological improvement. Today, corporate executives required to run in a pan-world circumstance by boosting the constraints beyond multinational and multi-cultural. The term "(global) leadership" is in continuous dispute, as the literature reveals numerous techniques to specify the term "global" (Mendenhall, Reiche, Bird, \& Osland, 2012) and likewise in discovering methods to identify in between global and domestic leadership (Osland et al., 2013). In response to this obscurity, Osland, Li and Wand (2014) laid out global leadership as:

The process of influencing others from multiple cultures to adopt a shared vision through structures and methods that facilitate positive change while fostering individual and collective growth in a context characterized by significant levels of complexity, flow and presence.

In elaboration, it is vital for global leaders to promote people representing multi-cultural, multi-lingual and multi-national; triggering them to adjust to the required business modification and inspire towards development in a global arena. According to observation Osland, Bird and Oddou (2012), there exists a large difference mainly in between global leadership and domestic leadership, especially in regard to the level of ability style and abilities required by the business world. According to Mendenhall et al. (2012) to be global leaders one ought to have the following qualities: 
- Complexity - refers to "the need for global leaders to navigate particularly complicated surroundings characterised via high levels of variety, interdependence and common and rapid alternate."

- Flow - refers to "the boundary spanning and relative depth and have an impact on their interactions with relevant ingredients that are needed of global leaders."

- Presence - describes "the necessity for global leaders to be physically on the market in numerous geographic locations."

\subsection{Background of the Study}

Because of the late 90s, accomplishments in business began to be related to leadership success. As observed by Stroh and Caliguiri (1998) around 60 multi-nationals after carrying out essential 3 practices worrying about the efficiency of the business concerned a typical understanding that global leadership development is the only service. Research study on Fortune 500 corporates highlighted the requirement of able global leadership as vital for business success (Gregersen, Morrison, \& Black, 1998). Since the most recent research study has actually substantiated the significance of global leadership. Another research study which was carried out by McKinsey (2012) likewise acknowledged global leadership as the vital aspect for business achievement and accepted as one in the middle of the 10 severe vital problems (the global leadership lacuna has actually been developed as the largest obstacle) identified on the World Economic Online Forum (WEF).

In today global circumstance, (Mendenhall et al., 2008), the corporates need to deal with multi-national, multi-lingual and multi-cultural challenges and to resolve these issues it is necessary to establish a global frame of mind in addition to global skills. The forces like variety, instability, unpredictability and connection are intensifying the responsibility for international leaders with brand-new capabilities that permit them to deal with and lead the business world with success (Marquardt \& Berger, 2000). Lots of corporates are dealing with deficiency executives, or possibly individuals with the hidden to become global leaders, as the supply does not certify the need requirements. A most current study carried out by

"Advancement Dimensions International and The Institute of Executive Advancement" covering twelve thousand business leaders covering seventy-six nations, likewise "discovered that most of the executive advancement specialists who reacted, mentioned the scarcity of global executive skill as the main service obstacle associated with globalization dealt with by their business (Smith, Caver, Saslow, \& Thomas, 2009)."

\subsection{Statement of the Problem}

Frequently, corporate executives operate in a quite complex circumstance, frequently performing business responsibilities which simultaneously broaden into a multi-national, multi-lingual and multicultural. The extraordinary practices these executives carry out manage them with crucial encounters and supplies them with likewise crucial natural incremental chances. Upon the big costs by the business for the advancement of leadership abilities, the proof is recommending the contrary. The existing small literature promoting that the procedure of transforming the practices into understanding that can be utilized to change as global leaders by the organisation executives is mainly undiscovered. 
Regardless of the truth that enhancement has actually been carried out in discovering the abilities that are required for organisation executives and the good manners or procedures through which those abilities might be established by the executives, research study has up until now not produced the definitive last results. More research study to check out the practices of company executives; the understanding gotten by those practices; needed abilities set to perform their functions effectively and the ways by which those abilities might be established in changing as international leaders is needed (Marquardt \& Berger, 2000; Mendenhall et al., 2008; Osland \& Fowl, 2008).

\subsection{Purpose of the Study}

The goal of this term paper for a short time to discover the private understandings and practices of corporate executives stated as important of their improvement as global leaders.

\subsection{Research Questions}

This research paper made an attempt to explore:

Primary

1. What practices do business executives define as crucial in the transformation as global leaders? Secondary

2. What do business executives describe the conversion of practices into knowledge that helped in the transformation as the global leaders?

3. How did business executives acquire empirical knowledge that commanded their transformation as global leaders?

\subsection{The Significance of the Study}

The ramifications of this research paper may be big due to the truth corporate executives told the real practices they carried out in their functions; acquiring understanding by those practices; discovering the capability which is needed for global leaders; obtaining those abilities through their knowing practices and utilizing them in their change into global leaders.

Numerous authors and scholars have actually predicted numerous capabilities which may be essential or vital for global leaders (Mendenhall \& Osland, 2002). Amongst the forecasted abilities an excellent number are promoted based upon keeping track of business leaders and multinationals, literature assessment and experiences with around the world companies. The existed proof from the research study is extremely minimal to develop the leadership skills for global leaders to be important for their function. The results of this term paper may assist in much better comprehending the experiences of corporate executives as crucial for their advancement; a much better know-how of what executives are reporting on gaining from these experiences; the vital abilities of global leadership needed in today's multinational corporate system and get a much better insight in what method global leaders provide on their knowing experience. 


\subsection{Limitations of the Study}

This research paper challenged with some restrictions. As it was a qualitative research study, the observations cannot be detailed for other populations external to the research study sample group. And this research study sample covers a couple of individuals and may not be an agent of various individuals who are likewise efficient global leaders.

As factors shared their individual practices, the research study counted on the level of people' selfcognizance and capability to increase their point of view on crucial global leadership efficiencies and their understandings in establishing the one's skills and abilities.

The research study depended upon the scientists' capability to acknowledge and well analyze factors' descriptions in explaining their practices. To reduce the effect of this situation, research study has actually utilized epoche to separate any previously developed concepts, beliefs, bias or understandings to make sure they are looked into with the open mind.

\section{Review of Literature}

\subsection{Globalisation}

Friedman (2005) provided the historical perspective of globalisation and identified its advancement into "3 elegant stages". In the main stage, in between 1492 and 1899, by and big, colonial powers bending their muscles to control and increase into various geographical areas. Throughout the mid-stage, extended in between 1800 and 2000, globalisation turned into an around the world phenomenon especially driven by international companies through the transformations brought in the transport, interaction networks and the application of info innovation into online trade. As far as the last stage worried, which started from the year 2000, which deals with "the newly found power for people to team up and contend globally-- individuals from each corner of the flat global."

Rodrik (1997) specified globalisation as "the global combination of markets for products, services and capital." Rosen et al. (2000) announced, in referral to globalisation, "the world is at as soon as without borderlines, multicultural and a growing hybrid of cultures." If, as Friedman (2005) figured out, "the world is flat, it's miles on the equivalent time a global of high turmoil and constant exchange (Marquardt \& Berger, 2000), in which business operates as if the entire world had actually been a single entity."

\subsection{Global Corporate}

Since the intro of the term 'global manager' by Bartlett and Ghoshal (1992) a long-lasting discussion has actually been started in business literature to reach a frequently accepted significance of the term 'international.' They included, multinationals began operating beyond nationwide limits, simultaneously pursuing around the world combining whilst securing domestic distinction. Parallelly, the expressions global, multi-national, global and international have actually remained in the use as interchangeable (Adler \& Bartholomew, 1992).

Basically, the exact same concept was propagated by Moran, Harris and Stripp (1993) while tracking an around the world boom phenomenon, corporates might adhere to any of 4 unique methods: 
- "A global method is a composite of a number of private foreign market entry strategies."

- "An international method is based upon portfolio preparation theory and includes examining which markets to go into, prevent, or exit."

- "A local method is centred around local fortress that focus on markets within the area's sphere of impact."

- "And, a worldwide method is an integrated system for handling business chances and hazards on an international basis."

\subsection{Leadership}

The term Leadership can be significantly used to extremely sophisticated advancement. This is among the terms that are extensively investigated and composed in the clinical discipline literature. As Antonakis, Cianciolo and Sternberg (2004), appropriately discussed: "Leadership is among social innovation's optimum took a look at phenomena." For Northouse (2004) "People are interested with the idea of leadership." According to Yukl (2006), "Leadership is a subject that has long animated pastime among human beings." Bass and Riggio (2006) revealed that there was a big interest displayed in leadership by both the academic community and the business world.

There built up in big descriptions, views and theories on leadership due to the extreme interest that has actually formed a huge frame of literature attempting to describe these various advancements. Both the academic community and the business world embraced numerous techniques in sharing the understanding of leadership based upon resemblances and in addition to significant differences.

Numerous differential meanings existed on leadership as there are numerous authors of the books on this topic. In the period of 50 years of his research study on leadership Yukl (2006) has actually specified it in 10 methods which making up into, "leadership as the procedure of affecting others to concur and comprehend about what requires to be done and how to do it and the procedure of assisting in cumulative and specific efforts to achieve shared goals."

\subsection{Global Leadership}

In concept, as much as current times, global leadership is thought about as an extension of the leadership therefore, the exact same theories of leadership were utilized in comprehending the idea of global leadership. The simplistic concept of global leadership made the circumstance exceptionally complex as it requires to think about the extra measurements of multi-cultural, multi-lingual and multi-national diversities.

As it is appropriately promoted by Avolio, (1998) as leadership is specified and comprehended in various methods in some cases contradictorily the exact same used to international leadership. Both ideas (leadership and global leadership) are similarly misinterpreted. Hollenbeck (2001) has actually provided a comprehensive angle of global leadership in his research study consisted of - technique, cross-culture, expatriation, proficiencies, leadership and adult knowing. In parallel with Bartlett and Ghoshal, he repeated that global leadership implies it is everything about working beyond borders, nevertheless, condemned them considering that they stopped working in acknowledging the important difference in between the borders of a nation and borders of a business and corporate activities. 


\subsection{Global Leadership Competencies}

Kets de Vries and Mead (1992) predicted skills that are important for global leadership: "a. capability for picturing, b. empowerment capability, c. develop and preserve organizational networks, d. cognitive intricacy, e. strength (from the tension literature) and f. cultural flexibility." To determine typical leadership abilities that are appreciated global, Yeung and Ready (1995) carried out a study on twelve hundred company executives dealing with 10 significant multinationals straddling 8 nations. They acknowledged the abilities of "capability to articulate a concrete vision, worths, technique; to be a driver for cultural and tactical modification; to accomplish outcomes; to empower others; to show a strong consumer orientation."

Likewise, Spencer and Spencer (1993) specified a proficiency "as an underlying attribute of a person that is causally associated with criterion-referenced reliable and/or exceptional efficiency in a task or circumstance." They likewise pointed out Boyatzis' description of proficiencies "as underlying qualities of individuals and show methods of believing or acting, generalizing throughout circumstances and withstanding for a fairly extended period of time."

\section{Methodology}

The phenomenological technique was used in this research study to find the genuine practices of corporate executives acknowledged as necessary in their change into global leaders. The narratives of these executives consist of - the practices observed in satisfying their functions; getting to understand from their practices; learning the vital ability and using those abilities in their improvement into global leaders - taken as the structure to deal with the requirement for research studies in global leadership behaviours, developmental designs and training approaches.

\subsection{Phenomenological Research study}

The approach of phenomenological research studies that has actually been picked due to the fact that it pursues the goal of phenomenological research study, i.e. to comprehend the activities of individuals within the social environments and likewise the approaches that are utilized at a time when the individuals planning to social phenomena corresponding to the objective of the research study. The global leadership arena is still developing, and thus, the extra research study is needed which restates the course of improvement into global leadership significantly, the abilities they think about vital to satisfying their functions as global leaders and the method they equate their practices into brand-new abilities and capabilities.

\subsection{System Analysis}

A discrete system of analysis was selected with the sample size of twelve corporate executives providing their duties as global leaders representing the global business at the time of their choice. The treatment of including the individuals to the sample list until the needed number was obtained (Miles \& Huberman, 1994). 


\subsection{Sample Choice}

The sample size covers twelve executives dealing with the significant multinationals primarily owning and/or running big branches in numerous countries, whose duties were worried about the jobs they needed to lead the company's positions and workers beyond the nationwide borders. Executives from numerous varied corporates were selected to acquire the outcomes that are most likely to be beneficial in discussing the procedure of the improvement into global leaders transversely the business world.

The choice requirements for taking part in this research study included: having minimum 5 years of experience in a top-level leadership function, acknowledged by the issue corporation as an effective executive and acquired approval to participate in the interview from the high-level leadership of the company. According to Creswell (1998), "purposeful criterion-based tasting works when a scholar picks to perform a phenomenological research study of several people who have actually experienced the exact same phenomenon."

\subsection{Information Collection}

The information was made up over an hour-long interview with the assistance of Moustakas' (1994) long interview approach. Prior to the interview, the epoche procedure was embraced for separating as lots of bias, preconceived ideas or beliefs, understanding and realities as possible, so that might not feel the ability to observe the experience of the individuals as they told. When grappling with the interview circumstance, all interviews begun with a temporary friendly orientation intended at developing a report and assuring the concern.

The information was gathered through the interview strategy that took care of the casual, interactive course and utilized open-ended concerns and observations. Offered that all analytical information from the interviews corresponded with the literature relating to global leadership abilities and the advancement of global leadership.

The global leadership arena is still developing, and thus, the extra research study is needed which restates the course of change into global leadership notably, the abilities they think about important to satisfying their functions as global leaders and the method they equate their practices into brand-new abilities and capabilities. Provided that all analytical information from the interviews corresponded with the literature relating to global leadership abilities and the advancement of global leadership. The information was made up over an hour-long interview with the assistance of Moustakas' (1994) long interview approach. All interviews started with a brief friendly orientation intended at developing a report and assuring the concern when grappling with the interview circumstance.

\section{Analysis}

The transcriptions of interviews were evaluated with the assistance of NVivo 8 software application. With the aid of Cogi method, the duplicated concepts and styles from the interviews were acknowledged. Specific techniques which were backed by Miles and Huberman (1994) were used for the functions of evaluating and analyzing the information gathered through interview, along with: 
1. Patterns and styles from the interviewees' observations and responses collared at the time of the interviews have actually been taken down. The numbers were designated to rapid find of releases and describe in the interview transcriptions and to lessen the effect of predispositions in the analysis.

2. Making clusters, for organizing and later on assuming ideas that had similar includes or details. This method can be used to view implying systems of the experience, assisting in the procedure of finding and enhancing textural descriptions and necessary leadership abilities

3. Memoing can be used throughout the procedure of coding to produce brand-new insights about styles and codes and their associations. Throughout the procedure of interview and analysis viewpoints and queries felt by the scientist were taped.

4. With the aid of the clusters, patterns and styles, one can acknowledge ramifications worrying crucial practices, acquiring understanding from the practices, learning the needed global leadership abilities and how service executives changed into global leaders by using global leadership capabilities, proficiencies or abilities.

After determining reasonings, the findings were compared to the global leadership abilities literature and global leadership enhancement literature and translated the findings in the written type.

\section{Findings and Discussion}

Moustaka's (1994) phenomenological technique was utilized to comprehend the procedure of improvement of the service executives into global leaders and its rapidness. All the narratives were straight reported by the company executives personally, felt as essential in pleasing their position and the methods executed to emerge as global leaders.

\subsection{Finding One: Practices, Abilities and Multi-cultural}

The individuals shared the procedure of obtaining the abilities they had to properly satisfy their position as global leaders by straight taking part in international and multi-cultural leadership practices that challenged their expectations and understandings and pressed their convenience zones. In the procedure of changing into global leaders, they got brand-new important insights, understandings and capabilities in the locations of social empathy, networking and the requirement for interest and an option to find out. Dalton (1998) and Dalton and Ernst (2004) suggested a range of difficult projects, "such as organisation journeys and long-distance multicounty jobs, working as cross-cultural staff member, expatriate projects, expatriate projects with supervisory obligations, repatriate tasks, tasks with local obligations, worldwide duty for a task, encouraging relationship and dealing with knowledgeable worldwide executives." All of these practices follow the practices that are pronounced by international leaders in this term paper.

\subsection{Discovering 2: Value and Worth of Cultural Level of Sensitivity, Relationships and Networks and Interest to Find Out}

From the understanding gotten by the service executives through their practices, the cultural level of sensitivity utilized to be the main style. The exact same discoveries had actually been echoed in McCall and Hollenbeck's (2002) research study into what efficient worldwide executives desire to discover. According to their findings "finding out to deal with cultural problems and adjusting to various cultures, 
discovering to manage complex and numerous relationships and growing personally in methods that boost adaption and development under hard situations, are all constant with the conclusions and findings draws from this research study paper."

\subsection{Finding 3: Special Set of Abilities to Efficiently Satisfy their Functions}

The individuals stressed that different abilities and abilities are necessary for satisfying the functions of global leadership effectively. These possible abilities and abilities are in the clusters of "a). Having actually come throughout unique cultures with remarkable worths, discovered themselves to handle an extra complex organisation job, these company executives have actually discovered that establishing and preserving the relationships should be proper.

\subsection{Finding 4: Interest, Openness and a Desire Discover}

The individuals revealed that there are specific favourable mindsets and special behaviours that may contribute to changing into global leaders. These likely abilities and abilities are in the clusters of mindsets like being inquisitiveness, openness and self-motivation to discover brand-new things paved the structure to change into global leaders by dealing with effectively brand-new difficulties in brandnew geographical settings. Having actually come throughout unique cultures with remarkable worths, discovered themselves to handle an extra complex company job, these organisation executives have actually discovered that establishing and preserving the relationships should be suitable. This capability includes discourse with individuals who are extremely modest and genuine to assist in the accomplishment of objectives in a reliable intercultural relationship.

\section{5 Discovering 5: Find Out Intuitively, Dynamically Utilizing advertisement hoc Knowing Approaches}

Active involvement in advancement activities, the individuals revealed that they have actually revealed instinctive behaviour, in a disorganized and unintended method. Wishing to comprehend developmental desires prior to they changed to basic jobs or research studies, they had a company tendency to delight in random, unsure and situational knowing. The advertisement hoc finding out technique appears appropriate in a complex and vibrant business world, where business executives provide their obligations successfully.

Moustaka's (1994) phenomenological method was utilized to comprehend the procedure of change of the service executives into global leaders and its rapidness. This research study paper is considerable as it tried and highlighted to bridge the lapses that existed in contemporary understanding worrying the practices that company executives observed to be crucial in their improvement as global leaders, the global leadership abilities and abilities that they had. All the narratives were straight reported by the company executives personally, felt as vital in pleasing their position and the methods executed to emerge as global leaders.

The individuals shared the procedure of getting the abilities they had to properly satisfy their position as global leaders by straight taking part in global and multi-cultural leadership practices that challenged their expectations and understandings and pressed their convenience zones. Mindsets like being self- 
motivation, inquisitiveness and openness to find out brand-new things paved the structure to change into global leaders by dealing with effectively brand-new difficulties in brand-new geographical settings.

\section{Summary}

The requirement for reliable service executives with essential abilities is long lasting and the fastchanging face of the existing business world has actually made the scenario direr. As efficient company executives, they need to never ever think twice to engage company operations in multi-national, multilingual and multi-cultural environments. By this procedure, every international business comprehends the abilities and abilities that are required for global leadership and the methods to support the global leaders.

\section{Acknowledgements}

This research was supported by TISHK International University. I thank Dr. Fatih Cura, Dean of The Faculty of Administrative Sciences and Economics and Mr. Karwan Hushyar, Head of Business \& Leadership Department who provided insight and expertise that greatly assisted the research, although they may not agree with all of the interpretations/conclusions of this paper.

Nobody has been more important to me in the pursuit of this project than the members of my family. I would like to thank my parents; whose love and guidance are with me in whatever I pursue. They are the ultimate role models. Most importantly, I wish to thank my loving and supportive wife, Ms. Kumari, and my only wonderful daughter, Ms. Gnana Satya Sri, who provide unending inspiration.

\section{References}

Adler, N. J., \& Bartholomew, S. (1992). Managing globally competent people. The Executive, 6(3), 5265.

Antonakis, J., Cianciolo, A. T., \& Sternberg, R. J. (2004). The nature of leadership. Thousand Oaks: Sage Publications.

Bartlett, C. A., \& Ghoshal, S. (1992). What is a global manager? Harvard Business Review, SeptemberOctober, 124-132.

Creswell, J. W. (1998). Qualitative Inquiry and Research Design: Choosing Among Five Traditions. Thousand Oaks: SAGE Publications, Inc.

Dalton, M. A. (1998b). Developing leaders for global roles. In C. McCauley, R. S. Moxley \& E. Van Velsor (Eds.), The Center for Creative Leadership handbook of leadership development (pp. 379-402). San Francisco: Jossey-Bass.

Dalton, M. A., \& Ernst, C. (2004). Developing leaders for global roles. In C. McCauley \& E. Van Velsor (Eds.), The Center for Creative Leadership Handbook of Leadership Development (pp. 361382). San Francisco: Jossey-Bass.

Friedman, T. L. (2005). The world is flat: A brief history of the twenty-first century. New York: Farrar, Straus and Giroux.

Gregersen, H. B., Morrison, A. J., \& Black, J. S. (1998). Developing leaders for the global frontier. Sloan Leadership Review, Fall, 21-32.

Hollenbeck, G. P. (2001). A serendipitous sojourn through global leadership literature. In W. H. Mobley \& M. W. McCall Jr (Eds.), Advances in global leadership (Vol. 2, pp. 15-47). Oxford:

Elsevier Science. 
Kets De Vries, M. F. R., \& Mead, C. (1992). The development of the global leader within the multinational corporation. In V. Pucik, N. M. Tichy \& C. K. Barnett (Eds.), Globalizing leadership. Creating and leading the competitive organization (pp. 187-205). New York: Wiley \& Son

Lane, H. W., Maznevski, M. L., \& Mendenhall, M. E. (2004). Hercules meets Buddha. In H. W. Lane, M. L. Maznevski, M. E. Mendenhall \& J. McNett (Eds.), The handbook of global leadership: A guide to managing complexity (pp. 3-25). Oxford: Blackwell.

Marquardt, M. J., \& Berger, N. O. (2000). Global leaders for the 21 st century. Albany, NY: State University of New York Press.

McCall, M. W., Jr., \& Hollenbeck, G. P. (2002). Developing global executives: The lessons of international experience. Boston: Harvard Business School Press.

Mendenhall, M. E., \& Osland, J. S. (2002). An overview of the extant global leadership research. Paper presented at the Academy of International Business, Puerto Rico.

Mendenhall, M.E., Reiche, B.S., Bird, A., \& Osland, J.S. (2012). Defining the 'global' in 53 global leadership. Journal of World Business, 47(4): 493-50.

Miles, M. B., \& Huberman, A. M. (1994). Qualitative Data Analysis: An Expanded Sourcebook. Thousand Oaks: SAGE Publications, Inc.

Moran, R. T., Harris, P. R., \& Stripp, W. G. (1993). Developing the global organization. Houston: Gulf Publishing.

Moustakas, C. E. (1994). Phenomenological research methods. Thousand Oaks: SAGE Publications, Inc.

Northouse, P. G. (2004). Leadership: Theory and Practice. Thousand Oaks: Sage Publications, Inc.

Osland, J. S., \& Bird, A. (2008). Process models of global leadership development Global leadership: Research, practice, and development (pp. 81-93). New York: Routledge.

Osland, J. S., Bird, A., Mendenhall, M. E., \& Osland, A. (2006). Developing global leadership capabilities and global mindset: A review. In G. K. Stahl \& I. Bjorkman (Eds.), Handbook of research in international human resource leadership (pp. 197-222). Cheltenham, UK: Edward Elgar.

Osland, J., Bird, A \& Oddou, G. (2012) The context of expert global leadership. Advances in Global Leadership (Vol. 7) (107-124). Bingley, UK: Emerald.

Osland, J. S., Li, M. \&Wang, Y. (2014). Introduction: The state of global leadership research. In Osland, J. S., Li, M., \& Wang, Y. (Eds). Advances in global leadership (Vol. 8) (1-16). Bingley, UK: Emerald Group Publishing.

Rodrik, D. (1997). Has globalization gone too far? Washington, D.C.: Institute for International Economics.

Rosen, R., Digh, P., Singer, M., \& Phillips, C. (2000). Global Literacies: Lessons on business leadership and national cultures. New York: Simon \& Schuster.

Smith, A., Caver, K., Saslow, S., \& Thomas, N. (2009). Developing the global executive: Challenges and opportunities in a changing world. Pittsburgh: Development Dimensions International, Inc.

Spencer, L. M., Jr., \& Spencer, S. M. (1993). Competence at work: Models for superior performance. New York: John Wiley \& Sons.

Stroh, L. K., \& Caligiuri, P. M. (1998). Increasing global competitiveness through effective people leadership. Journal of World Business, 33(1), 1-16.

Yeung, A. K., \& Ready, D. A. (1995). Developing Leadership Capabilities of Global Corporations: A Comparative Study in Eight Nations. Human Resource Leadership (1986-1998), 34(4), 529.

Yukl, G. (2006). Leadership in Organizations (Sixth ed.). Upper Saddle River: Pearson Education, Inc. 